ISSN No. 0974-035X

An indexed refereed \& peer-reviewed journal of higher education

Towards Excellence

UGC-HUMAN RESOURCE DEVELOPMENT CENTRE

Gujarat University, Ahmedabad-380009, Gujarat, India

\title{
UPSELLING STRATEGY: A REVIEW
}

\section{Dr. Mehal Pandya}

\section{Prof. Abhigna Dholakia}

\begin{abstract}
The purpose of this study is to systematically review the existing literature on Upselling and its major impacts on consumer behaviours. In addition, this study seeks to shed light on trends and dynamics in Service sector and Retail sector, so as to find the effectiveness of Upselling strategy. A systematic literature review of published peer-reviewed articles on Upselling was conducted. A comprehensive search strategy was applied on different databases, including Google Scholar, JSTOR, ScienceDirect, Pro quest, Emerald, Academia and the likes and the renowned articles were then selected from leading journals published between 1995 and 2020 . The research finding suggest that a company may get the profitability at times but not all the time using the upselling strategy. To get the profitability firm should focus on Customer loyalty and satisfaction of the consumer for that the results show that there is a need to replace the Upselling strategy with Up-buying strategy in studies focused on consumer behaviour analysis. The studies included in this review are extensively based on peer-reviewed 40 articles published in high-ranked marketing journals and articles within a span of 30 days which may be perceived as a limitation in the present study. The relationship between Upselling and the Customer satisfaction in many occasion prove to be negative hence there is a requirement of change in strategy so as to shift focus from salesforce centric strategy to customer centric strategy, of which the companies will have a considerable practical implication aiming to increase profit and simultaneously increase in Customer Lifetime value along with Customer Loyalty. The authors hereby expect the current review to significantly find the effectiveness of Upselling strategy in consumer behaviour. This review provides a strong contribution to Upselling literature by recommending the need to find the effectiveness of Upselling strategy in Services and Retail sector. No exclusive paper is available which evaluates effectiveness of UpSelling strategy which can be further studied for strategic purpose.
\end{abstract}

Keywords: Consumer behaviour, Consumer Retention, Consumer Loyalty, Profitability, Upselling, Effectiveness.

\section{Paper type: Literature review}




\section{Introduction}

Consumer behaviour study is required for the Segmentation and Targeting strategies. (Selçuk Köylüoğlu, Saliha Eken İnan, \& Acar, 2018) mentioned that Consumer behaviour is a situation that ends up in purchasing or not. To make the study productive marketer needs to device a marketing strategy. Marketing strategy differs with each segment and every marketer is interested in repeat purchaser hence strategy for acquiring a customer and strategy for retaining the customer differ completely, here the role of Customer Relationship Management is extremely important as (Ekhlassi, Maghsoodi, \& Mehrmanesh, 2012) used (Swift, 2001) definition of CRM as an "Organizational approach to understanding and influencing on customer behavior through a meaningful relationship in order to improve customer acquisition, retention, loyalty and profitability processes." (Abu Daqar \& Smoudy, 2019) explains Customer acquisition and Customer retention as Customer Acquisition is a process of identifying the potential customers and building awareness for a brand with short term profits which require different marketing strategy and Customer Retention aims at repeat purchases and long term relationship with customer which require more of personal selling to retain the customers and more focus on customer service. But the Marketer is also interested in profitability. Cross selling and Up selling strategies provide a wider scope to the marketer to earn profit at less service to the existing customer.

\section{Upselling}

As per the Federal Trade Commission (FTC) defines upselling in the context of telemarketing as "soliciting the purchase of goods or services following an initial transaction during a single telephone call," the same thing was explained by (Aydin \& Ziya, 2008) and (Sharma, M.,Sharma,k, 2015) who defined Upselling as a technique offering the customer an opportunity to purchase additional product after the recent purchase for a better experience. Upselling is also seen as a reversal of decision from original to superior service option in many industries as pointed out by (Wibke, H. et. al., 2017). Which (Singer, 2015)stressed upon that Up-selling is the promotion of a higher level product or service than the one the customer is thinking of buying. On similar ground, Stephan Schiffman defines Up-selling "is what happens when you take the initiative to ask someone who already has purchased something you offer to purchase more of it - or more of something else". Superior option suggests moving up the ladder as (Kubiak, Bernard, Weichbroth, \& Powel, 2010) mentioned Up-selling means moving "up" to a more expensive product or Service. Many researchers have also stressed an importance of Sales persons' role in Upselling like, (Sharma, M.,Sharma,k, 2015) defined Upselling as strategy wherein the seller makes special efforts and induces the customer to buy an upgradable version or an expensive additional items aiming to make a profitable deal for the firm. Profitability aspect was addressed by (Ni,J.,Shen,Q.,Zhu,T., 2015) as well as it can lead to high profit margin. But he also gave an indication that upselling is negatively correlated with customer satisfaction. Because many times allegations have been made that upselling is nothing but inflating the price with a new extension as cited by (Steele, 2013) The researcher aims at identifying the upselling potential and effectiveness for the following purposes: 


\section{Objectives:}

1. To critically evaluate and provide an integrated, synthesized overview of the current stage of knowledge in the field of Up-selling strategy to marketers and customers.

2. To identify the research gap and future insights in making Up-Selling more effective both for marketer and customers.

\section{Research Methodology}

The research methodology includes a systematic literature review (SLR) to determine the dynamics of the field, potential research gaps and future research expectations. SLR is a method that brings together and critically evaluates publications on the subject; it helps to assess the replicability of findings and their possible inconsistencies (Siddawayet al.,2019). The authors reviewed the articles, books, and 40 Research papers published in the marketing journals between 1995 and 2020.

Process

\begin{tabular}{|l|l|}
\hline Flow & Results \\
\hline Topic Formulation & Based on purpose \\
\hline Study design & Literature review, Conceptual \\
\hline Sample & $\mathbf{4 0}$ \\
\hline Data collection & $\begin{array}{l}\text { Source: Pro quest, SSRN, Google Scholar, } \\
\text { Science Direct, Emerald, Economics } \\
\text { Times, Forbs, Harvard Business Review }\end{array}$ \\
\hline Data Analysis & $\begin{array}{l}\text { Critically evaluate the Pros and cons of } \\
\text { implementation of upselling strategy both } \\
\text { for customers and marketer. }\end{array}$ \\
\hline Reporting & $\begin{array}{l}\text { Reviewing literature, inferences, } \\
\text { conclusion, limitations and Future } \\
\text { research }\end{array}$ \\
\hline
\end{tabular}

Search Strings

\begin{tabular}{|l|l|}
\hline Theme & Search String \\
\hline Stakeholders & $\begin{array}{l}\text { Customers, customers, competitors, users, } \\
\text { buyers, service provider, employees }\end{array}$ \\
\hline Engagement & $\begin{array}{l}\text { CRM, Customer Equity, Relationship } \\
\text { Marketing, customer retention }\end{array}$ \\
\hline Sectors & Service, Retail, E commerce \\
\hline
\end{tabular}


Towards Excellence: An Indexed, Refereed \& Peer Reviewed Journal of Higher Education /

Dr. Mehal Pandya \& Prof. Abhigna Dholakia / Page 157-168

Inclusion and Exclusion Criteria

\begin{tabular}{|l|l|l|}
\hline Criterion & Inclusion & Exclusion \\
\hline Study type & $\begin{array}{l}\text { Empirical, Conceptual, } \\
\text { Conference Proceedings, } \\
\text { Articles }\end{array}$ & \\
\hline Language & English & Any other language \\
\hline Date & $1995-2020$ & Before 1995 \\
\hline Relevance & Service and Retail sector & Other Sectors \\
\hline
\end{tabular}

\section{Evolution of Upselling}

Relationship marketing, first appearing in the marketing literature in 1983, has been defined by (Berry, 1995) as "attracting, maintaining and - in multi-service organizations - enhancing customer relationships." The focus was shifted from customer acquisition to Customer Retention, when organizations learned that it costs, on average, five to ten times more to find a new customer rather than retaining one. (Borna, 2000). Customer Retention is a part of Customer Relationship management (CRM) (Wubben, 2009) and one of the most common strategies for customer retention is the practice of Up-Selling. As (Wirtz, J.,Lovelock,C., 2016) pointed out that to move the customer up the ladder from Lead to Iron category, upselling has turned out to be the most cost effective channel to communicate and motivate the existing customers. Apart from these concerns (Peter, 2013) found out that the increasing number of distribution and marketing channels which expose savvy Internet shoppers the ability to find the best deal, Dramatic swings in economic conditions, Mobile and e-commerce channels have shortened the booking cycle, limiting forecasting ability for revenue and reservations. The same point of transformation was pointed out by (Sharma, M.,Sharma,k, 2015)as market scenario, bargaining power of customers and suppliers, the widespread of distribution channels as given a way to Upselling. The same has been defined in graphical way as below:

\section{A Model developed by Researchers: Upselling}




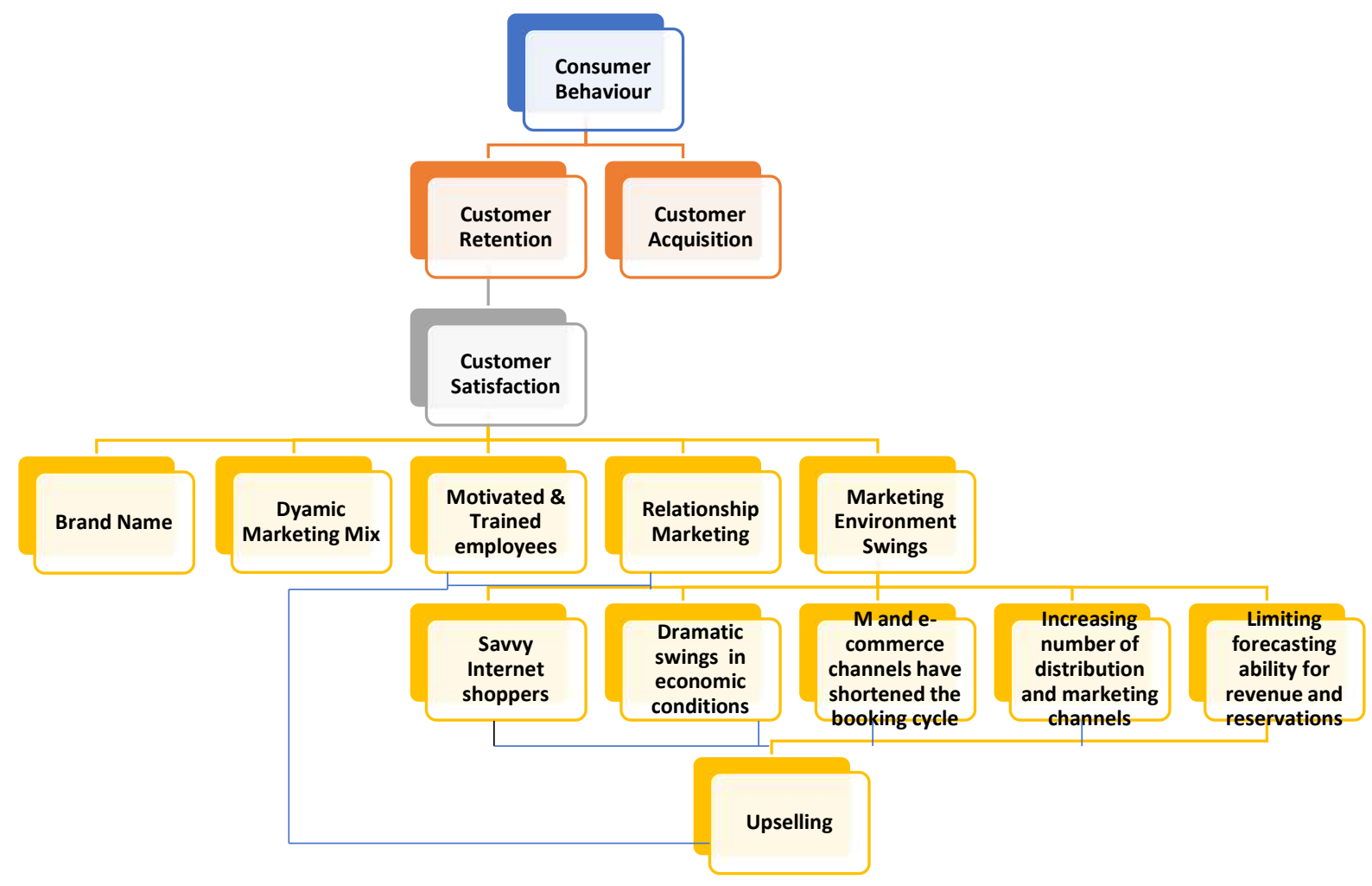

\section{Scope of Upselling}

For the upsell stage to occur, (Aydin \& Ziya, 2008) implied that a customer has to first arrive first to buy the regular item. And the additional item should be a substitute of the original product as cited by (kwiatkowska, 2018) that products and services sold as part of up-selling are substitute goods, which means that they substitute each other and meet the same needs.(Cohn) addressed in one of the article that upselling is a popular sales strategy in many industries which encourages a customer to purchase a more augmented model in the same product family with additional features. Apart from features timing is also critical, offer the higher priced product as soon as the customer has already committed to purchasing an item. (kwiatkowska, 2018) studied that one of the principles of up-selling is the fact that it is used when the customer has not yet purchased the basic product and what is more crucial is that the purchase transaction has not ended. Upselling also helps in expanding a business relationship with the firm over the long term. In the ongoing process of improvement, for the customer relation management it should not be restricted only to the sale of more products (Kubiak, Bernard, Weichbroth, \& Powel, 2010).

\section{Effectiveness of Upselling}

As the aim for any marketer is to increase revenue and minimise the cost cited by (Guillet, 2019) that Upselling has the potential to increase revenues (Kamakura. W.A, 2008) and cut down selling costs (Rothfeder, 2003). Up-selling focuses on increasing the transaction size per customer rather than acquiring new customers, which helps to cut down the selling cost 
(Ebster,C.,Wagner,U.,Valis,S., 2005). The similar point was discussed by (Andrews) that upselling strategy increases average order size, and turns single-buyers into multi-buyers .The similar point was raised by (Aydin \& Ziya, 2008) that to increase revenue per each customer visit is one of the goal of upselling. but this objective is served only when the retailers typically try to sell each customer an additional product related to the one the customer just bought, and the other purpose of Upselling could be as cited by (Aydin,G.,Ziya,S., 2005) and (Aydin \& Ziya, 2008) liquidation of excess inventories wherein the marketer identifies slow moving product having excessive inventory and tries to liquidate the same to the customers who has just bought the products. But sometimes it is not about getting profit or getting rid of unwanted inventory as pointed by (Sharma, M.,Sharma,k, 2015)that to deliver delightness as a part of customer post purchase behaviour Upselling is useful. It is also treated as a driver for sales productivity. (Khwaja, 2014) A firm using upselling has one valuable piece of information about the customer who is about to receive the upsell offer, hence in upselling, knowing that the customer bought a product at a certain price has informational value to the firm when offering the promotional product. (Aydin \& Ziya, 2008)

\section{Upselling in Service Sector}

As cited by (Wirtz, J.,Lovelock,C., 2016) services having features of intangibility, perishability, variability and inseparability requires to maintain cordial relations with customers through relationship marketing to ensure loyalty, for that the service provider needs to segment using selectivity and tiering the customers based on the value created by them to the firm. To deepen the relations to each tier of customers firms offer bundling, cross selling and upselling as part of strategies with the help of CRM software through their share of wallet. (Dai, Bing Tian, 2014) studied that a cable TV provider uses the concept of tiering the customers as per their respective value because for cable TV service providers to retain their customers, instead of launching promotions for all customers, to create value for their customers they need to specialize their promotions and make marketing strategies accordingly hence encourage them to purchase more services. This process is called targeted upselling as (Kim, 2002) pointed out in telecom services, customer usage history is treated as valuable information to generate new revenue through targeted upselling strategies, targeted upselling increases the willingness-to-pay of specific customers as the provider's marketing strategies will be tailor-made for them, they will be more satisfied. To satisfy the customers, employees play a vital role as mentioned by (Khwaja, 2014)with respect to car rental services that there is exist a causal relationship between engagement and sales productivity in the form of upselling, as employees often interact directly with customers hence engagement based on customer-centric issues and among employees that directly face customers has a stronger effect on upselling than all other forms of employee engagement. Apart from employee engagement, (Wiesman, 2010) studied the influence of performance feedback on upselling which turns out to be positive one. (Gallego \& Stefanescu, 2009) cited that in case of managing the demand and supply upgrades and upsells are especially useful to tackle the mismatches. To manage the capacity decisions in long run and the daily fluctuations in demand, Revenue Management in pricing is required, as an upgradeable and upsell product allows the seller to fulfil it at the same price with a more desirable substitute from a prespecified set of alternative products. For service provider upselling is a need of an hour because the competition is intense and the 
database maintenance cost has decreased as mentioned by (Kim, B., Kim, S., 1999), it has become difficult to acquire customers so firms are focusing on retaining customers using the database try to sell more of the products / services (Upselling) and other related products/services( Cross selling). (Gupta, 2018) studied demographic variables and found that technology is major contributor in deciding on upselling for e- banking, which enables banks in providing customized offering to right customers. In many of the services as researched by, (Wibke, H. et. al., 2017) that upselling is a two-stage process wherein the process of selecting the first purchase affects the final decision. The contemporary service provider wants to serve his customer holistically that is possible only through upselling and no other technique can serve the purpose. (Peter, 2013). Whereas (Wibke, 2016)researched hat upselling is three step process. (Manchanayake, 2019) stated in their research that telecommunication industry is a kind of industry where for the purpose of churn reduction and stabilizing the customer base, upselling is used. In case of service cancellation, finding late-arriving customers who agree to pay a significantly higher price compared to the price paid by the early-arriving customers can also be done as a part of Upselling strategy. (Xie \& Gerstner, 2005). Upselling can be beneficial if the selling firm faces a mismatch between supply and demand. (Steinhardt, 2012)

\section{Upselling in Retail sector}

According to Philip Kotler- "Retailing includes all the activities involved in selling goods or services to the final customers for personal, non- business use." According to David Gilbert -Any business that directs its marketing effort towards satisfying the final consumer based upon the organization of selling goods and services as a means of distribution. The retailing industry is being driven by a dynamic equation with the changes in the environment such as an increasing number of dual-income families, a decreasing amount of available time for shopping, technological revolutions, and shopping choices (Pookulangara, 2008). Up-selling means selling more expensive items, such as steaks or seafood instead of chicken, which likewise increases sales per check. (Tan \& Netessine, 2019) One of the prime examples for that is a Mobile phone. Mobile phone is a kind of a product which the contemporary generation keeps on changing and every time they change, they always go for the upgraded version with more features and better specifications. So, while getting more value, the customer ends up paying a little more money each time he or she buys a new and a better phone. If the retailer enjoys Monopoly then also he can use upselling as in the case of Apple. As referred by, (Geradin \& Katsifis, 2020)Apple is a monopolist in the market for app distribution on iOS, hence there is no strong competitor, such as Android app stores or the web. As a result of that app developers have to go to Apple as it is the gateway to reach iOS users. This position gives Apple leverage and power to engage in anti-competitive practices. Apple charges excessive fees for the services it provides. Along with Monopoly, Revenue management play an important role in upselling strategy implementation as (Gallego \& Stefanescu, 2009) studied that mismatches that occur when capacity decisions are fixed for the long run, for example the travel and leisure industries, as the number of seats on a plane, the number of hotel rooms of a given size, the number of cruise cabins with a view, and the capacity of a theatre are all fixed and difficult to change in the short run as demand fluctuates over time. Mismatches may occur due to seasonality effects. As studied by (Kubiak, Bernard, Weichbroth, \& Powel, 2010) that to increase value of single sales transaction and to increase 
switching cost, upselling technique is presented, as the behaviour of consumer is driven by the Attitude towards behaviour and Theory of Reasoned action play a major role as mentioned by (Pookulangara, 2008)Many catalogue retailers such as Lillian Vernon, based in Rye, NY (1999), Corona Cigar Co., based in Ocoee, FL (Ferriolo2003), toy and novelty cataloguer Oriental Trading Co., and apparel cataloguer DM Management (Miller 1995) use upselling. Online retailers like Buy.com and Amazon along with Traditional retailers use the practice of upselling by recommending additional products to customers who just purchased an item. Most people can recall being offered an additional items that will be perfect for the purchased item. (Aydin \& Ziya, 2008) Capacity providers often give upgrades free of charge when it is to their advantage to do so. However, car rental companies such as Hertz are starting to push customers to voluntarily buyup to higher grade products by offering upgrades at attractive prices at the time of fulfilment. Similarly, airlines may offer attractively priced business class upgrades to economy customers either at check-in or just before completing the purchase of an economy e-ticket. (Gallego \& Stefanescu, 2009)Upselling is a common practice in business that is associated with high profit margin. Yet empirical evidence suggests that upselling is negatively correlated with customer satisfaction.

\section{Inferences}

Effectiveness of upselling programme can be achieved by providing the right offer to the right customer at right time to ensure profitability and Customer loyalty together. From the study the researchers have inferred that by trying to sell something which is not relevant to the customers or if the timing is not proper of offering the augmented product, that can affect adversely to the brand image for which customer may doubt the credibility and may switchover to the alternatives. Instead marketer should focus on creating a recurring income from relevant products wherein the customers involvement is high, which can solve their problems and provide them assurance and guarantee which is more important in upsell. So, it is better to have a customer driven transaction so rather than training an employee, one should train the customer so that he willingly up-buy the product which enhances his/her loyalty along with company's profitability. As studied by (Parihar, 2012)the customers are empowered to share their product/service/brand experiences in a whole new way and there has been a fundamental power shift in the traditional CEM model: from being 'company centric', to the version 2.0 of CEM which has now truly become 'customer centric'. The marketer needs to create situations like, scarcity of the product or service demanded, manage the capacity with respect to demand so that customer willingly would pay more to get the desired product or service. For that he has to work with AIDA model (Attention, Interest, Desire and Action) The AIDA model was developed by the American businessman, E. St. Elmo Lewis, in 1898. Which has been modified frequently over the years. The product or service should have a distinctive place in the Desire stage so that customer would readily pay more to get the offering. Which calls for shift from Upselling to Up-buying. 


\section{Conclusion}

The great thing about upsells either in services or in retail is not only higher profit margin but also retaining the customer longer can also be the objective, from the literature reviewed ,the researchers have reached to the conclusion that to serve the purpose of profitability and loyalty both simultaneously, firm must shift focus from upselling to up-buying as the customer if willingly purchases higher priced product or service he would not only be profitable but would help firm in combating the churn. As long as the firm provides superior value with strategic selling it can have pleased customers. To make a transition from upselling to up-buying firm must consider factors like the training to employees and customers, the nature of the product, position in the desire stage, scarcity of offering, monopoly, revenue and capacity management, quality of offering, social and psychological factors like, attitude and motives.

\section{Limitations and Further Research}

The studies included in this review are extensively based on peer-reviewed 40 articles published in high-ranked marketing journals and articles within a span of 30 days which may be perceived as a limitation in the present study. It is recommended to further research drivers and consequences of up buying strategy for the strategic purpose in Consumer behaviour 
Towards Excellence: An Indexed, Refereed \& Peer Reviewed Journal of Higher Education /

Dr. Mehal Pandya \& Prof. Abhigna Dholakia / Page 157-168

\section{References}

Abu Daqar, M., \& Smoudy, A. (2019). The Impact of Consumer Buying Behavior on Customer. International Review of Management and Marketing, 9(4), 39-46.

Andrews, K. (n.d.). Extending Upselling and Cross-Selling Efforts.

Aydin, G., \& Ziya, S. (2008). Pricing Promotional Products Under Upselling. Manufacturing and Service Operations Management, 10(3), 360-376. doi:10.1287/msom.1070.0187

Aydin,G.,Ziya,S. (2005). Upselling a Promotional Product Using CustomerPurchase Information.

Berry, L. L. (1995). Relationship Marketing of Services - Growing Interest, Emerging Perspectives. Journal of the Academy of Marketing Science, 23(4), 236-245.

Borna, C. (2000). “Combating Customer Churn,” . Telecommunications, 34(3), 83-85.

Cohn, C. (n.d.). A Beginner's Guide To Upselling And Cross-Selling.

Dai, Bing Tian. (2014). How Can Consumer Preferences Be Leveraged for Targeted Upselling in Cable TV Services? Pacific Telecommunications Council (PTC'14). Research Collection School Of Information Systems.

Ebster,C.,Wagner,U.,Valis,S. (2005). The Effectiveness of verbal prompts on sales. Journal of Retail and consumer service, 13, 169-176.

Ekhlassi, A., Maghsoodi, V., \& Mehrmanesh, S. (2012). Determining the integrated marketing communication tools for different stages. International Journal of Information and Electronics Engineering,, 2(5), 761-770.

Gallego, G., \& Stefanescu, C. (2009). Upgrades, Upsells and Pricing in RevenueManagement. Management Science, 1-32.

Geradin, D., \& Katsifis, D. (2020, May 3). The antitrust case against the Apple App Store.

Guillet, B. D. (2019). Online upselling: Moving beyond offline upselling in the hotel industry. International Journal of Hospitality management.

Gupta, N. (2018). "Influence of Demographics on Employees' Perception for Cross-Selling and Up-Selling of eBanking Services,". Economics and Applied Informatics, "Dunarea de Jos" University of Galati, Faculty of Economics and Business Administration, .

Jian, N.,Qiaowei S.,Ting Z. (2015). Upselling versus Upsetting Customers? A Model ofIntrinsic and Extrinsic Incentives.

Kamakura. W.A. (2008). Cross selling-Offering the right product to the right customer at the right time. Journal of Relationship Marketing, 41-58.

Khwaja, A. Y. (2014). Sales Productivity and Employee Engagement: Evidence from Upselling in the Car Rental Industry. 
Towards Excellence: An Indexed, Refereed \& Peer Reviewed Journal of Higher Education /

Dr. Mehal Pandya \& Prof. Abhigna Dholakia / Page 157-168

Kim, B., Kim, S. (1999). Measurinf Upsselling potential of Life insurance consumers:Application of Stochastic Frontier model. Journal of Interactive Marketing, 13(4).

Kim, S. (2002). Firm characteristics influencing the extent of electronic billing adoption: an empirical study in the U.S. telecommunication industry. Telematics and Informatics, , 19(3), 201-203.

Kubiak, Bernard, F., Weichbroth, \& Powel. (2010). Cross- And Up-selling Techniques In ECommerce Activities. Journal of Internet Banking and Commerce, 15(3), 1-7.

kwiatkowska, J. (2018). cross-sellIngandup-sellIng In a bank. Copernican Journal of Finance \& Accounting, 7(4), 59-70.

Manchanayake, S. e. (2019). Potential Upselling Customer Prediction Through User Behavior Analysis Based on CDR Data. IEEE. doi:10.1109/ICIIS47346.2019.9063278

Ni,J.,Shen,Q.,Zhu,T. (2015). Upselling versus Upsetting Customers? A Model ofIntrinsic and Extrinsic Incentives.

Parihar, M. (2012). Social Media - The Final Frontier in Customer Experience Management". Nirma International Conference on Management. Ahmedabad: SSRN.

Peter, T. (2013). When More is More: Exploring Upselling as a Sales \& Marketing Tactic. Hospitality Sales \& Marketing Association International.

Pookulangara, S. (2008). EXPLAINING CONSUMERS' CHANNEL-SWITCHING BEHAVIOR USING THE THEORY OF PLANNED BEHAVIOR.

Rothfeder, J. (2003, January). Trend: Cross-selling. CIO Insight. . Retrieved from https://www.cioinsight.com/c/a/Trends/Trend-CrossSelling.

Selçuk Köylüoğlu, Ü., Saliha Eken İnan, Ö., \& Acar, E. (2018). A Research on Consumer Behaviour: Konya Sample. China-USA Business Review, 17(6), 316-323.

Sharma, M.,Sharma,k. (2015). UPSELLING -A HIGH REVENUE TECHNIQUE FOR HOTELS. International Journal of Busness Management, 3(7), 62-68.

Singer, A. (2015, July 9). 7 tips for cross-selling and up-selling. The Telegraph- Herald. Dubuque, Lowa.

Steele, F. (2013, September 6). How to spot the housing hype: 'Upselling' is becoming more widespread. The Times. London, London, UK.

Steinhardt, C. G. (2012). Integrated revenue management approaches for capacity control with planned upgrades. European Journal of Operational Research, 223, 380-391.

Swift, R. (2001). Accelarating Customer Relationships: Using CRM. New Jersey:Prentice Hall : Upper saddle river .

Tan, T. F., \& Netessine, S. (2019). When You Work with a Superman, Will You Also Fly? An Empirical Study of theImpact of Coworkers on Performance. SSRN. 
Towards Excellence: An Indexed, Refereed \& Peer Reviewed Journal of Higher Education /

Dr. Mehal Pandya \& Prof. Abhigna Dholakia / Page 157-168

Wibke, H. (2016). Upselling or Upsetting? studies on behavioural consequences of upsell offers on service encounters.

Wibke, H. et. al. (2017). Supersize me!” The effects of cognitive effort and goal frame on the persuasiveness of upsell offers. Journal of Service Management, 28(3), 541-562.

Wiesman, D. (2010, July 30). The Effects of Performance Feedback and Social Reinforcement on Up-Selling at Fast-Food Restaurants.

Wirtz, J.,Lovelock,C. (2016). Service Marketing,people, technology, strategy. New Jersey: World Scintific.

Wubben, M. (2009). Analytical CRM-Developing and Maintaining Profitable Customer relationships in Non contractual setting. Springer.

Xie, J., \& Gerstner, E. (2005). Service Escape: Profiting From Customer Cancellations. SICS conference. UC Berkeley: University of Pittsburgh.

Dr. Mehal Pandya, Associate Professor - B.K. School of Professional and Management Studies, Ahmedabad

Email Id: pandya.mehal@gmail.com,Contact 9712940069

\&

Prof. Abhigna Dholakia, Research Scholar - B.K. School of Professional and Management Studies, Gujarat University, Ahmedabad

Assistant Professor (LJIMBA), Email Id: abhignavaishanv@gmail.com,

Contact Number: 9879113791 